\title{
Locally advanced rectal cancer: management challenges
}

\author{
This article was published in the following Dove Press journal: \\ OncoTargets and Therapy \\ 13 October 2016 \\ Number of times this article has been viewed
}

\section{RF Kokelaar \\ MD Evans \\ $M$ Davies \\ DA Harris \\ J Beynon}

Department of Colorectal Surgery, Singleton Hospital, Swansea, UK
Correspondence: RF Kokelaar Department of Colorectal Surgery, Singleton Hospital, Sketty Lane, Sketty, Swansea SA2 8QA, UK

Tel +44 I792 285030

Email rory.kokelaar@wales.nhs.uk
Abstract: Between $5 \%$ and $10 \%$ of patients with rectal cancer present with locally advanced rectal cancer (LARC), and 10\% of rectal cancers recur after surgery, of which half are limited to locoregional disease only (locally recurrent rectal cancer). Exenterative surgery offers the best long-term outcomes for patients with LARC and locally recurrent rectal cancer so long as a complete (R0) resection is achieved. Accurate preoperative multimodal staging is crucial in assessing the potential operability of advanced rectal tumors, and resectability may be enhanced with neoadjuvant therapies. Unfortunately, surgical options are limited when the tumor involves the lateral pelvic sidewall or high sacrum due to the technical challenges of achieving histological clearance, and must be balanced against the high morbidity associated with resection of the bony pelvis and significant lymphovascular structures. This group of patients is usually treated palliatively and subsequently survival is poor, which has led surgeons to seek innovative new solutions, as well as revisit previously discarded radical approaches. A small number of centers are pioneering new techniques for resection of beyond-total mesorectal excision tumors, including en bloc resections of the sciatic notch and composite resections of the first two sacral vertebrae. Despite limited experience, these new techniques offer the potential for radical treatment of previously inoperable tumors. This narrative review sets out the challenges facing the management of LARCs and discusses evolving management options.

Keywords: rectal cancer, exenteration, pelvic sidewall, sacrectomy

\section{Introduction}

In the UK, 14,000 new cases of rectal cancer are diagnosed every year, and 40,000 in the US, of which between $5 \%$ and $10 \%$ are locally invasive (T4) at presentation. ${ }^{1,2}$ Tumors extending beyond the total mesorectal excision (TME) plane may be suitable for a multivisceral approach if a complete (R0) resection is achievable. ${ }^{3-5}$ An R0 resection is the single greatest predictor of outcome after surgery for rectal cancer, and any surgery must be undertaken with the intention of achieving histologically clear resection margins..$^{4-7}$ Unfortunately, despite optimal surgery and adjuvant therapies, $10 \%$ of patients experience a local recurrence, of which approximately half will have a locoregional disease only. ${ }^{8}$

The surgical management of locally advanced (LARC) and locally recurrent rectal cancers (LRRC) has developed since Brunschwig first described pelvic exenteration for cervical cancer in $1948 .{ }^{9}$ Currently, the 5-year survival rate for LARC is between 52\% and $65 \%,{ }^{10,11}$ but is significantly lower in LRRC where 5-year survival is between 35\% and $50 \%{ }^{12,13}$ Survival for both LARC and LRRC is still worse if the tumor is not centrally located in the pelvis, especially if it extends to the pelvic sidewall or high sacrum where it is usually deemed inoperable. ${ }^{14}$ 
These poor outcomes have led surgeons to seek novel approaches to anatomically unfavorable tumors and revisit previously discounted operations for highly selected patients. ${ }^{15-18}$ Currently, a number of pioneering procedures are being developed in specialist centers around the world, although their utilization is limited to a very small number of highly specialized units.

\section{Aim}

The aim of this review was to consider the current surgical approaches to anatomically unfavorable primary and recurrent rectal tumors beyond-TME margins, with a particular emphasis on emerging surgical techniques in this field.

\section{The current approach to beyond-TME tumors The MDT}

The management of cancer has developed significantly since the Calman-Hine Framework was established in 1995, advocating a site-specific multidisciplinary team (MDT) organization of care involving a broad range of clinical specialties and support services. ${ }^{19}$ This principle has been further extended in the management of advanced pelvic malignancies to include specialists across an even wider spectrum where individual expertise may be required on a case-by-case basis for multivisceral or radical resections. The recent international consensus statement on the management of rectal cancers beyond-TME recommends that all LARC and LRRC should be managed in a super-specialized MDT. ${ }^{1}$ In the spirit of this extended framework, our own unit established the Swansea Pelvic Oncology Group in 1999, bringing together colorectal surgeons and oncologists with colleagues in urology, gynaeoncology, plastic-reconstructive, and orthopedic surgery, a practice now well established in most centers dealing with complex cases. ${ }^{20}$ The foundation of super-specialist centers allows for the development of expertise in managing what are, within the normal practices of an MDT, uncommon cases, with the aim of developing a high-volume and highquality service.

\section{Staging}

The ultimate goal of exenterative surgery is to achieve a R0 resection. In node-negative patients with locally advanced disease in whom clear margins are achieved we have reported a 53\% 5-year survival rate. ${ }^{20}$ This surgery should only routinely be undertaken where the intent is to achieve a histologically clear resection, as there is no survival advantage following an R1 resection (microscopic margin involvement) or palliative "debulking" procedures compared to no surgery. ${ }^{21,22}$ It is, however, appreciated that there will always be a small number of patients who are better palliated with resection. To this end, accurate multimodal preoperative staging (magnetic resonance imaging [MRI]/computed tomography [CT]/endorectal ultrasound scan [ERUS]) is imperative, combined with experienced clinical assessment of the tumor under anesthetic or in the clinic. ${ }^{23-25}$ The detection of LRRC by radiology alone may be challenging in the postsurgical postradiotherapy pelvis, and thus serial imaging and judicious use of $\left[{ }^{18} \mathrm{~F}\right]$ fluorodeoxyglucose positron-emission tomography-CT may be advantageous, although further evidence is required for routine implementation. ${ }^{26}$ Histologically confirmed recurrence should be sought as the gold standard of diagnosis in LRRC, particularly as the patients may be subjected to extensive ablative procedures, which carry significant morbidity if not potential mortality.

\section{Chemoradiotherapy}

In order to achieve a R0 resection, neoadjuvant therapy may be employed where margins are threatened. Neoadjuvant long-course chemoradiotherapy (CRT) (45-50.4 Gy plus augmented 5-fluorouracil regimens according to local guidelines) has been demonstrated to improve the operability of previously inoperable LARC and reduce local recurrence rates. ${ }^{27-29}$ A number of additional techniques in boosting pre-operative radiotherapy dose have been trialed, including high-dose-rate endorectal brachytherapy (HDREBT) and intraoperative radiotherapy (IORT). ${ }^{30,31}$ Despite HDREBT showing promising results in down-staging $\mathrm{T} 2 / 3$ rectal tumors prior to surgery, there is a paucity of evidence to support its implementation in beyond-TME tumors. ${ }^{32,33} \mathrm{~A}$ recent review indicates that local disease control, diseasefree, and overall survival may be improved with IORT in LARC and LRRC, although wound complications were higher. ${ }^{34}$ This review does, however, acknowledge the heterogeneity of the studies included and does not assert recommendations for the implementation of IORT nor does it address the specific challenges of beyond-TME tumors. The role of neoadjuvant radiotherapy in the context of new chemotherapy regimens has however been challenged and is being examined further in the ongoing PROSPECT trial, which is investigating the efficacy of neoadjuvant chemotherapy alone in patients with cT2N1 or cT3N0-1 tumors who are eligible for sphincter sparing TME. ${ }^{35,36}$ The benefits of preserving oncological outcomes while avoiding radiotherapy-related local toxicity and the associated side effects would be significant both to the patient and surgeon 
operating in a radiation-naïve field; however, the outcomes from this study will offer little evidence to support the management of beyond-TME tumors as this group is excluded from the study. Radiotherapy for LRRC in the radiation-naïve pelvis is, however, recommended prior to surgery, although its implementation in a previously irradiated field remains controversial and lacking in evidence. ${ }^{37}$ Adjuvant CRT may be indicated where circumferential margins are involved, in node-positive disease, or where extramural vascular invasion is demonstrated.

\section{Exenteration and reconstruction}

The choice of surgery depends on the site of the tumor and structures into which it is invading. There is currently no consensus in terminology for pelvic multivisceral surgery for primary tumors as most classification systems were developed for recurrent tumors, although the principles are broadly transferrable. In our unit, we advocate the classification of locally advanced tumor extension as anterior, posterior, lateral sidewall, or composite, in keeping with previous systems and the practice of other UK units. ${ }^{4}$ Standard multivisceral resections for LARC and LRRC may be considered as either total pelvic exenteration or posterior pelvic clearance, depending on the patient's gender, previous surgery, and extent of invasion into the pelvic organs and sacrum. ${ }^{38,39}$ To ensure an $\mathrm{R} 0$ resection, significant reconstruction of viscera and soft tissues may be required following radical resection, including bladder reconstruction/formation of ileal conduit and reconstruction of the perineal defect. Local rotational and pedicled myocutaneous flaps are particularly useful in reconstructing the perineum and filling the dead-space in the exenterated pelvis, but should only be undertaken by experienced teams. ${ }^{40-42}$ Currently, there is limited experience of vaginal/external genital reconstruction in the context of rectal cancers, but where indicated should be performed using myocutaneous flaps as these offer reduced morbidity. ${ }^{43}$

\section{Patient selection}

The technical feasibility of operating on LARC and LRRC must be tempered against the physiological burden of lengthy (often up to 12 hours if extensive reconstruction is necessary) and challenging operations. ${ }^{4}$ Patients with inoperable metastatic disease or who are physiologically unfit (American Society of Anesthesiologists [ASA] score IV/V) are clearly not suitable for this arduous surgery. Assessing a patient's fitness for surgery is best undertaken by an anesthetist who has experience of working within the pelvic oncology MDT and who is able to assess the relevance of preexisting cardiopulmonary disease. The role of objective physiological testing in managing patients with advanced pelvic malignancies is under review, but cardio-pulmonary exercise testing may be valuable where judgments are equivocal, especially in the elderly patient. ${ }^{44,45}$ The attitude of the patients prior to their disease process and the ablative surgery that they will be subjected to cannot be ignored. It is imperative that they have a positive mental attitude and the will to survive.

\section{Current limitations}

Despite the advances in multivisceral surgery for LARC and LRRC, there are some anatomical considerations that are either relative or absolute contraindications to surgery and a curative approach to management. ${ }^{1}$ The relative factors that determine potential operability are: extension of the tumor through the sciatic notch, involvement of the iliac vessels that would necessitate vascular reconstruction, and involvement of the sacrum above the $\mathrm{S} 2 / 3$ junction. When involved by tumor, it is deemed that these anatomical challenges either make an $\mathrm{R} 0$ resection technically unachievable or carry so much morbidity that surgery would not be in the patient's best interests. Bilateral sciatic nerve involvement and circumferential bone involvement remain absolute contraindications to surgery.

Survival in this group or patients is abysmal and most patients are best managed palliatively, and so developing novel techniques to improve the potential operability of these anatomically unfavorable tumors beyond-TME, or revisiting previously discarded operations, may be the only other options. Undertaking operations on such cases require careful consideration on a patient-by-patient basis, and surgery should only be attempted where an $\mathrm{R} 0$ resection can reasonably be expected. Currently, there are only a handful of MDTs worldwide with the expertise to attempt such surgery, although there is growing evidence that solutions may be forthcoming.

\section{New avenues}

Considering the prerequisite of an $\mathrm{R} 0$ resection, the surgical approach to excision of pelvic sidewall tumors may involve the iliac vessels, sciatic nerve, and bony pelvis, or combinations thereof. Patients with LRRC invading the lateral sidewall have significantly poorer survival compared to local recurrence at other sites, reported at 5\%-7\% at 5 years with palliative or no treatment. ${ }^{46,47}$ This poor prognosis has led to a growing interest in revisiting more radical surgical options for sidewall tumors as well as novel techniques being sought. 


\section{Previously discarded operations}

Outside of the practice of colorectal surgery, pelvic sarcoma surgery (bony and soft tissue), where there is involvement of the sciatic nerve or iliac vessels, has traditionally employed external hemipelvectomy (EHP) or hindquarter amputation $2{ }^{48,49}$ These mutilating operations have traditionally had a high level of associated morbidity, although rehabilitation and reconstructive advances have improved outcomes considerably. ${ }^{50}$ Oncological outcomes are mixed due to the diversity of tumors these procedures are employed to treat, but some series have yielded mobilization rates of $85 \%$ following EHP in highly selected patients. ${ }^{51}$ One small series of eight female patients undergoing EHP for LRRC or primary rectal cancer involving the lumbosacral nerves demonstrated a $75 \% \mathrm{R} 0$ resection rate and $62 \% 5$-year survival, with acceptable morbidity and $50 \%$ mobilization with prosthesis. ${ }^{52}$ The patients in this series, however, were highly selected, with a median ASA score of 2 and median body mass index of $21.5 \mathrm{~kg} / \mathrm{m}^{2}$.

An alternative to EHP in pelvic sarcoma where there is no neurovascular involvement is internal hemipelvectomy (IHP) ${ }^{53,54}$ This procedure, and its variants, allows the lower limb to be spared and has demonstrated good oncological outcomes in appropriately selected sarcoma patients and carries less morbidity than EHP. ${ }^{55,56}$ There is no published experience of IHP in rectal cancer and only a single case report in its utilization for a locally invasive recurrent rightcolon cancer involving the iliac crest. ${ }^{57}$

\section{En bloc sciatic notch procedures}

Given the limitations of extensive bony pelvic resection for rectal tumors, the focus of sidewall surgery has moved to more limited but highly targeted resections of tumor and adjacent structures en bloc, but without the necessity to fully dissect a whole field or mutilate the patient, although this may entail a higher $\mathrm{R} 1 / 2$ rate. A retrospective study of multivisceral resections for rectal cancer, including limited sidewall excisions (vascular only), has demonstrated an $\mathrm{R} 0$ resection rate of $53 \%$, with $46 \%$ overall remaining disease-free at an average of 30 months. ${ }^{17}$ In this series, a bespoke approach was taken to lateral sidewall excisions depending on the exact extent of the tumor, preserving as much tissue as possible, and 25 patients (69\%) were alive at a mean follow-up of 19 months. These results are broadly comparable to the experience in sarcoma surgery, where good long-term graft patency has also been reported utilizing the superficial femoral vein. ${ }^{58-60}$ Although a classification system exists for vascular involvement in lower limb and pelvic sarcoma patients, it is not intended as a guide to judging operability; instead, high-quality vascular imaging and support from specialist vascular team are important in managing such patients. ${ }^{61}$

There is limited previous experience with composite sciatic excision in rectal cancer surgery as it has previously been regarded as a contraindication to a radical approach. Kameyama et al reported a series of three patients who underwent sciatic excision due to intolerable pain as a result of LRRC involving the sciatic nerve. ${ }^{62}$ Each patient reported an improvement of symptoms and was able to ambulate when discharged from hospital, but two died within 16 months of surgery due to recurrence or metastasis. The third patient was only followed-up for 7 months. Shaikh et al recently reported a case series of six highly selected patients undergoing a novel extended lateral pelvic sidewall excision procedure for either primary or recurrent rectal or anal cancer, each achieving an R0 resection. ${ }^{63,64}$ This standardized technique comprises an extra-pelvic phase and an abdominal phase that converge on the sciatic notch from either side, allowing en bloc resection of tumor. Half of the patients required excision of the sciatic nerve due to tumor involvement, and all patients had the internal iliac vessels ligated either above or below the level of the superior gluteal artery. In this small series, there was no immediate mortality and only minor morbidity, with the range of hospital length of stay 14 to 33 days. All patients were able to mobilize on discharge, those having had sciatic nerve excision requiring additional physiotherapy and an orthosis. Despite the promising results, it is important, however, to note that this initial small series was conducted by an MDT with extensive experience of operating on and rehabilitating patients who had undergone extensive softtissue excisions for bony and soft-tissue sarcomas. A good functional result can, however, be expected in a majority of well-selected patients following sciatic excision provided sufficient support is provided, in keeping with the experience in sarcoma surgery. ${ }^{65,66}$

\section{High sacral resection}

Resection of the sacrum below or at the level of S3 has been shown to be oncologically beneficial and functionally/ morbidly acceptable. ${ }^{10,65,67,68}$ Sacral resection is normally performed in the prone position and the amputation should be one segment above the one involved. However, primary or recurrent tumor involvement at or above the S2 level has been considered a contraindication for resection due to the high prevalence of unacceptable autonomic and somatic neurological deficit, ${ }^{69}$ although bowel and bladder function, 
as well as mobility with minimal aid, has been shown to be recoverable in a large proportion of patients with appropriate rehabilitation..$^{70,71}$ Additionally, sacral resection involving the cranial half of the $\mathrm{S} 1$ vertebral body renders the pelvis unstable and thus requires extensive pelvic reconstruction with internal fixation and grafting that is generally considered unacceptable. $^{72}$

High sacral resection does, however, offer a significant survival advantage if $\mathrm{R} 0$ resection can be achieved. In initial investigations, Wanebo et al reported a 5-year survival rate of $25 \%$ of patients following sacrectomy compared to $3 \%$ receiving palliative therapy alone (although the palliative therapy employed in this study has now been superseded by superior treatments). ${ }^{73}$ In another series, the same author reported an $85 \%$ R0 rate among high sacrectomy cases with $31 \%$ of 5 -year survival. ${ }^{74}$ In a limited series of nine patients who received a high sacral resection, including one at L5 level, Dozois et al reported a 100\% R0 rate and median survival of 31 months. ${ }^{75}$ More recently, Milne et al demonstrated an $\mathrm{R} 0$ resection rate of $72 \%$ in 100 patients undergoing pelvic exenteration with sacrectomy (61 rectal, 17 anal, and four other cancers) with $38 \%$ and $30 \%$ overall and disease-free survival, respectively. ${ }^{76} \mathrm{R} 0$ rate was not affected by the extent of sacral resection, although high sacrectomy did increase the rate of neurological deficit $(P=0.04)$. The complication rates of such operations are, however, high (74\%), especially for wound healing and pelvic infection in a post-radiotherapy field, although there was no in-hospital mortality in this series.

The clear survival benefit of $\mathrm{R} 0$ sacral resection has prompted innovation in limited sacral resection. Shaikh et al described a novel high subcortical sacrectomy (HiSS) procedure for primary and recurrent tumors invading the anterior cortex of $\mathrm{S} 1$ and/or $\mathrm{S} 2$ in a series of five patients. In this procedure, the anterior central sacral column (limited by the lateral aspect of the sacral foramina) is lifted from the wider sacrum to a depth not exceeding $10 \mathrm{~mm}$ of cancellous bone, delivering the anterior sacrum en bloc with invading tumor and anterior structures, preserving the posterior portion and alar of the sacrum and thus biomechanical integrity, avoiding the need for reconstruction. ${ }^{77,78}$ Each of the five patients in this small study achieved an $\mathrm{R} 0$ resection and all had no evidence of local recurrence at between 12 and 20 months follow-up. Due to the position of tumors, some patients required excision of the sacral nerve roots at the foramina, and thus neurological compromise could not be completely avoided. Concerns regarding bleeding during this procedure due to the high vascularity of the pre-sacral fascia and cancellous bone were managed by the liberal use of high-powered diathermy and bone wax. Blood loss was reported as ranging between 500 and 1,500 $\mathrm{mL}$, but no details were provided regarding need for intraoperative blood transfusion, which has previously been shown to increase the incidence of tumor recurrence. ${ }^{79}$ One patient had a Clavien-Dindo postoperative complication of IIIb (anastomotic leak), but there was no in-hospital mortality.

Figure 1 illustrates the anatomical principles of the HiSS procedure in a male patient with a primary high-rectal carcinoma treated in our unit by abdominoperineal resection with HiSS and vertical rectus abdominis myocutaneous flap. The tumor can be observed on the MRI extending to and involving the anterior sacral fascia at the S1-S2 level, beyond the planes of TME, with the illustration demonstrating the subcortical resection. In this case, an R0 resection was achieved; the procedure lasted 7 hours and 13 minutes, the patient required no blood product transfusion, and was discharged fully ambulatory on day 9 without immediate complication.

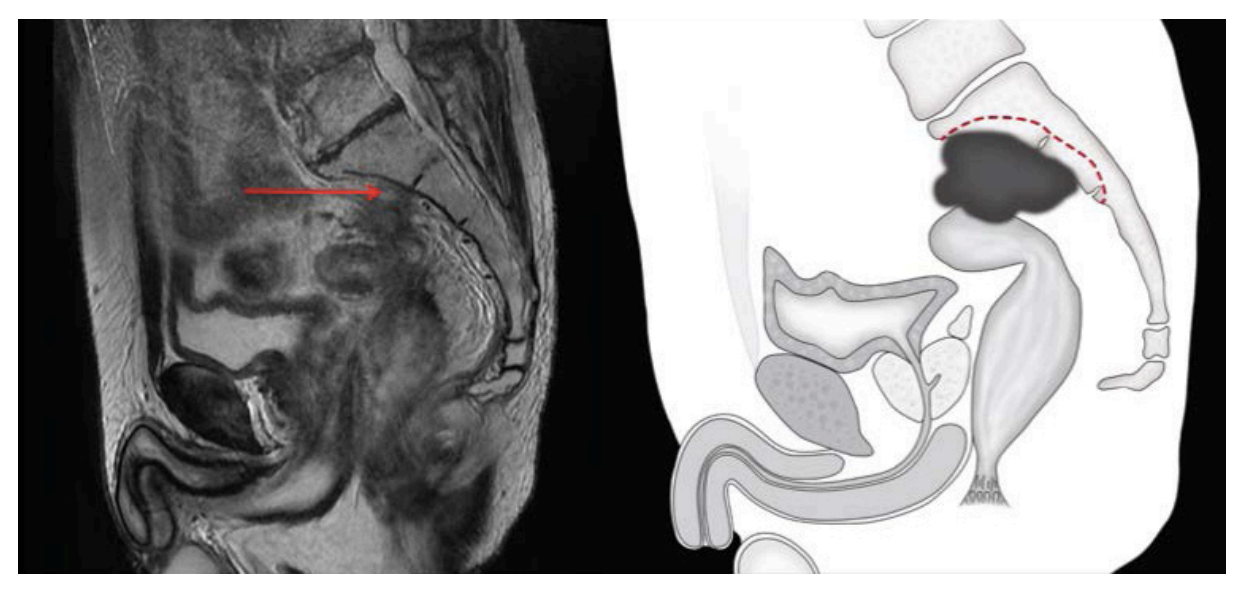

Figure I T2 sagittal magnetic resonance imaging demonstrating a high-rectal carcinoma extending to the pre-sacral fascia SI-S2 level (arrow). Note: Illustration of the high subcortical sacrectomy resection (dashed line) in the same patient. 
Brown et al reported a further composite procedure for LRRC following high anterior resection involving the left sacrum from mid-S1 to S2/3 levels, S1 and S2 nerve roots, piriformis, and internal iliac vessels. ${ }^{80}$ In this single case, a posterior approach to the sacrum was performed by medial detachment and lateral reflection of the glutei. Radiologically guided osteotomies were then created just distal to the superior endplate of S1 and at the middle of the body of S3 on the affected side only. These osteotomies were then connected vertically in the midline and laterally to free the block of sacrum, completing a limited unilateral sacral disconnection prior to abdominal exenteration. The benefit of this technique is that it avoids complete high sacrectomy, thus maintaining the stability of the pelvis and structural integrity of the sacrum, allowing for full weight bearing without reconstruction. The authors acknowledge that this approach was potentially hazardous, as it requires an approach onto the internal iliac vessels without proximal control.

\section{Smaller resections of the bony pelvis}

There is limited published experience of minor bony resections of the pelvis in the colorectal literature. Wanebo et al reported eight limited resections of the bony pelvis (five involving ileum or ischium, and three involving pubic rami or symphysis) as part of a larger mixed cohort of LARC and LRRC, of which four patients survived a minimum of 3 years. ${ }^{81}$ Lopez and Luna-Pérez reported a mixed cohort of 34 pelvic tumors (including rectal, gynecological, urological, and sarcoma) involving the bony pelvis, achieving an $\mathrm{R} 0$ resection rate of $88 \%$ and a cancer-specific 5-year survival of $52 \% .{ }^{82}$ Despite the heterogeneity of patients and procedures in these two studies, the overriding principle that an $\mathrm{R} 0$ resection is the most significant factor in predicting survival is maintained and that composite pelvic resections are feasible for a limited number of patients.

\section{Conclusion}

Despite recent advances in exenterative surgery for LARC and LRRC, there are aspects of disease management that need further development and assessment of efficiency. Of particular interest are tumors affecting the pelvic sidewall and high sacrum, which have generally been regarded as inoperable and therefore with an associated poor prognosis. Of particular concern are the anatomical challenges associated with extended pelvic resections and the consequent morbidity resulting from sacrificing important neuronal, vascular, and skeletal structures in search of an $\mathrm{R} 0$ resection. Any decision to operate in such circumstances must be weighed carefully against the risks of disability and morbidity. To this end, novel approaches to en bloc resections are being developed in highly specialized centers with appropriate expertise, although the number of patients suitable and centers able to provide such services are currently too small to determine whether long-term outcomes and wider implementation of these techniques will be recommended. What is undoubtedly clear, however, is that patients with complex LARC or LRRC should be managed in super-specialized centers if radical surgery is to be pursued in order to give the patients the best chance of cure.

\section{Disclosure}

The authors report no conflicts of interest in this work.

\section{References}

1. Beyond TME Collaborative. Consensus statement on the multidisciplinary management of patients with recurrent and primary rectal cancer beyond total mesorectal excision planes. Br J Surg. 2013;100(8): 1009-1014.

2. Sineshaw HM, Jemal A, Thomas CR Jr, Mitin T. Changes in treatment patterns for patients with locally advanced rectal cancer in the United States over the past decade: An analysis from the National Cancer Data Base. Cancer. 2016;122(13):1996-2003.

3. Bhangu A, Ali SM, Brown G, Nicholls RJ, Tekkis P. Indications and outcome of pelvic exenteration for locally advanced primary and recurrent rectal cancer. Ann Surg. 2014;259(2):315-322.

4. Davies ML, Harris D, Davies M, Lucas M, Drew P, Beynon J. Selection criteria for the radical treatment of locally advanced rectal cancer. Int J Surg Oncol. 2011;2011:678506.

5. Smith JD, Nash GM, Weiser MR, Temple LK, Guillem JG, Paty PB. Multivisceral resections for rectal cancer. Br J Surg. 2012;99(8):1137-1143.

6. Wibe A, Rendedal PR, Svensson E, et al. Prognostic significance of the circumferential resection margin following total mesorectal excision for rectal cancer. Br J Surg. 2002;89(3):327-334.

7. Bernstein TE, Endreseth BH, Romundstad P, Wibe A; Norwegian Colorectal Cancer Group. Circumferential resection margin as a prognostic factor in rectal cancer. Br J Surg. 2009;96(11):1348-1357.

8. Spratt JS Jr, Watson FR, Pratt JL. Characteristics of variants of colorectal carcinoma that do not metastasize to lymph nodes. Dis Colon Rectum. 1970;13(3):243-246.

9. Brunschwig A. Complete excision of pelvic viscera for advanced carcinoma. A one-stage abdominoperineal operation with end colostomy and bilateral ureteral implantation into the colon above the colostomy. Cancer. 1948;1(2):177-183.

10. Yamada K, Ishizawa T, Niwa K, Chuman Y, Aikou T. Pelvic exenteration and sacral resection for locally advanced primary and recurrent rectal cancer. Dis Colon Rectum. 2002;45(8):1078-1084.

11. Kecmanovic DM, Pavlov MJ, Kovacevic PA, Sepetkovski AV, Ceranic MS, Stamenkovic AB. Management of advanced pelvic cancer by exenteration. Eur J Surg Oncol. 2003;29(9):743-746.

12. Palmer G, Martling A, Cedermark B, Holm T. A population-based study on the management and outcome in patients with locally recurrent rectal cancer. Ann Surg Oncol. 2007;14(2):447-454.

13. Hansen MH, Balteskard L, Dørum LM, Eriksen MT, Vonen B; Norwegian Colorectal Cancer Group. Locally recurrent rectal cancer in Norway. Br J Surg. 2009;96(10):1176-1182.

14. Yamada K, Ishizawa T, Niwa K, Chuman Y, Akiba S, Aikou T. Patterns of pelvic invasion are prognostic in the treatment of locally recurrent rectal cancer. Br J Surg. 2001;88(7):988-993.

15. Boyle KM, Sagar PM, Chalmers AG, Montefiore DS, Cairs A. Surgery for locally recurrent rectal cancer. Dis Colon Rectum. 2005;48(5):929-937. 
16. Varker KA, Wanebo HJ. Salvage of pelvic recurrence of colorectal cancer. J Surg Oncol. 2010;101(8):649-660.

17. Austin KK, Solomon MJ. Pelvic exenteration with en bloc iliac vessel resection for lateral pelvic wall involvement. Dis Colon Rectum. 2009; 52(7):1223-1233.

18. Harji DP, Griffiths B, McArthur DR, Sagar PM. Surgery for recurrent rectal cancer: higher and wider? Colorectal Dis. 2013;15(2):139-145.

19. The Expert Advisory Group on Cancer to the Chief Medical Officers of England and Wales. A policy framework for commissioning cancer services: A report by the Expert Advisory Group on Cancer to the Chief Medical Officers of England and Wales. London, UK: Department of Health; 1995.

20. Nguyen DQ, McGregor AD, Freites O, et al. Exenterative pelvic surgery - eleven year experience of the Swansea Pelvic Oncology Group. Eur J Surg Oncol. 2005;31(10):1180-1184.

21. Hunter JA, Ryan JA Jr, Schultz P. En bloc resection of colon cancer adherent to other organs. Am J Surg. 1987;154(1):67-71.

22. Bhangu A, Ali SM, Darzi A, Brown G, Tekkis P. Meta-analysis of survival based on resection margin status following surgery for recurrent rectal cancer. Colorectal Dis. 2012;14(12):1457-1466.

23. MERCURY Study Group. Diagnostic accuracy of preoperative magnetic resonance imaging in predicting curative resection of rectal cancer: prospective observational study. BMJ. 2006;333(7572):779.

24. Augestad KM, Lindsetmo RO, Stulberg J, et al; International Rectal Cancer Study Group (IRCSG). International preoperative rectal cancer management: staging, neoadjuvant treatment, and impact of multidisciplinary teams. World J Surg. 2010;34(11):2689-2700.

25. Puli SR, Reddy JB, Bechtold ML, Choudhary A, Antillon MR, Brugge WR. Accuracy of endoscopic ultrasound to diagnose nodal invasion by rectal cancers: a meta-analysis and systematic review. Ann Surg Oncol. 2009;16(5):1255-1265.

26. Kamel IR, Cohade C, Neyman E, Fishman EK, Wahl RL. Incremental value of CT in PET/CT of patients with colorectal carcinoma. Abdom Imaging. 2004;29(6):663-668.

27. Roh MS, Colangelo LH, O’Connell MJ, et al. Preoperative multimodality therapy improves disease-free survival in patients with carcinoma of the rectum: NSABP R-03. J Clin Oncol. 2009;27(31):5124-5130.

28. Bosset JF, Calais G, Mineur L, et al. Enhanced tumorocidal effect of chemotherapy with preoperative radiotherapy for rectal cancer: preliminary results - EORTC 22921. J Clin Oncol. 2005;23(24):5620-5627.

29. Rodel C, Grabenbauer GG, Matzel KE, et al. Extensive surgery after high-dose preoperative chemoradiotherapy for locally advanced recurrent rectal cancer. Dis Colon Rectum. 2000;43(3):312-319.

30. Vuong T, Belliveau PJ, Michel RP, et al. Conformal preoperative endorectal brachytherapy treatment for locally advanced rectal cancer: early results of a phase I/II study. Dis Colon Rectum. 2002;45(11): 1486-1493; discussion 1493-1495.

31. Kusters M, Valentini V, Calvo FA, et al. Results of European pooled analysis of IORT-containing multimodality treatment for locally advanced rectal cancer: adjuvant chemotherapy prevents local recurrence rather than distant metastases. Ann Oncol. 2010;21(6):1279-1284.

32. Nout RA, Devic S, Niazi T, et al. CT-based adaptive high-dose-rate endorectal brachytherapy in the preoperative treatment of locally advanced rectal cancer: Technical and practical aspects. Brachytherapy 2016;15(4):477-484.

33. Vuong T, Devic S. High-dose-rate pre-operative endorectal brachytherapy for patients with rectal cancer. J Contemp Brachytherapy. 2015; 7(2):183-188.

34. Mirnezami R, Chang GJ, Das P, et al. Intraoperative radiotherapy in colorectal cancer: systematic review and meta-analysis of techniques, longterm outcomes, and complications. Surg Oncol. 2013;22(1):22-35.

35. Bossé D, Mercer J, Raissouni S, et al. PROSPECT Eligibility and Clinical Outcomes: Results From the Pan-Canadian Rectal Cancer Consortium. Clin Colorectal Cancer. 2016;15(3):243-249.

36. Schrag D, Weiser MR, Goodman KA, et al. Neoadjuvant Chemotherapy Without Routine Use of Radiation Therapy for Patients With Locally Advanced Rectal Cancer: A Pilot Trial. J Clin Oncol. 2014;32(6): 513-518.
37. Glimelius BL. The role of preoperative and postoperative radiotherapy in rectal cancer. Clin Colorectal Cancer. 2002;2(2):82-92.

38. Ferenschild FT, Vermaas M, Verhoef C, et al. Total pelvic exenteration for primary and recurrent malignancies. World J Surg. 2009;33(7): $1502-1508$.

39. Gannon CJ, Zager JS, Chang GJ, et al. Pelvic exenteration affords safe and durable treatment for locally advanced rectal carcinoma. Ann Surg Oncol. 2007;14(6):1870-1877.

40. Christensen HK, Nerstrøm P, Tei T, Laurberg S. Perineal repair after extralevator abdominoperineal excision for low rectal cancer. Dis Colon Rectum. 2011;54(6):711-717.

41. Hinojosa MW, Parikh DA, Menon R, Wirth GA, Stamos MJ, Mills S. Recent experience with abdominal perineal resection with vertical rectus abdominis myocutaneous flap reconstruction after preoperative pelvic radiation. Am Surg. 2009;75(10):995-999.

42. Anderin C, Martling A, Lagergren J, Ljung A, Holm T. Short-term outcome after gluteus maximus myocutaneous flap reconstruction of the pelvic floor following extra-levator abdominoperineal excision of the rectum. Colorectal Dis. 2012;14(9):1060-1064.

43. McArdle A, Bischof DA, Davidge K, Swallow CJ, Winter DC. Vaginal Reconstruction Following Radical Surgery for Colorectal Malignancies: A Systematic Review of the Literature. Ann Surg Oncol. 2012;19(12): 3933-3942.

44. Older P, Hall A, Hader R. Cardiopulmonary exercise testing as a screening test for perioperative management of major surgery in the elderly. Chest. 1999;116(2):355-362.

45. Belardinelli R, Lacalaprice F, Carle F, et al. Exercise-induced myocardial ischaemia detected by cardiopulmonary exercise testing. Eur Heart J. 2003;24(14):1304-1313.

46. Avradopoulos KA, Vezeridis MP, Wanebo HJ. Pelvic exenteration for recurrent rectal cancer. Adv Surg. 1996;29:215-233.

47. Garcia-Aguilar J, Cromwell JW, Marra C, Lee SH, Madoff RD, Rothenberger DA. Treatment of locally recurrent rectal cancer. Dis Colon Rectum. 2001;44(12):1743-1748.

48. Carter SR, Eastwood DM, Grimer RJ, Sneath RS. Hindquarter amputation for tumours of the musculoskeletal system. J Bone Joint Surg Br. 1990;72(3):490-493.

49. Karakousis CP, Emrich LJ, Driscoll DL. Variants of hemipelvectomy and their complications. Am J Surg. 1989;158(5):404-408.

50. Senchenkov A, Moran SL, Petty PM, et al. Predictors of complications and outcomes of external hemipelvectomy wounds: account of 160 consecutive cases. Ann Surg Oncol. 2008;15(1):355-363.

51. Apffelstaedt JP, Driscoll DL, Spellman JE, Velez AF, Gibbs JF, Karakousis CP. Complications and outcome of external hemipelvectomy in the management of pelvic tumors. Ann Surg Oncol. 1996;3(3): 304-309.

52. Nielsen MB, Rasmussen P, Keller J, Laurberg S. Preliminary experience with external hemipelvectomy for locally advanced and recurrent pelvic carcinoma. Colorectal Dis. 2012;14(2):152-156

53. Lackman RD, Crawford EA, Hosalkar HS, King JJ, Ogilvie CM. Internal hemipelvectomy for pelvic sarcomas using a T-incision surgical approach. Clin Orthop Relat Res. 2009;467(10):2677-2684.

54. Apffelstaedt JP, Zhang PJ, Driscoll DL, Karakousis CP. Various types of hemipelvectomy for soft tissue sarcomas: complications, survival and prognostic factors. Surg Oncol. 1995;4(4):217-222.

55. Ham SJ, Schraffordt Koops H, Veth RP, van Horn JR, Eisma WH, Hoekstra HJ. External and internal hemipelvectomy for sarcomas of the pelvic girdle: consequences of limb-salvage treatment. Eur J Surg Oncol. 1997;23(6):540-546.

56. Wirbel RJ, Schulte M, Mutschler WE. Surgical treatment of pelvic sarcomas: oncologic and functional outcome. Clin Orthop Relat Res. 2001(390):190-205.

57. Lopes Rossi ABM, Ferreira FdO. Internal hemipelvectomy in the treatment of recurrent carcinoma of the colon. Dis Colon Rectum. 1997;40(12) 1504-1507.

58. Fueglistaler P, Gurke L, Stierli P, et al. Major vascular resection and prosthetic replacement for retroperitoneal tumors. World J Surg. 2006; 30(7):1344-1349. 
59. McKay A, Motamedi M, Temple W, Mack L, Moore R. Vascular reconstruction with the superficial femoral vein following major oncologic resection. J Surg Oncol. 2007;96(2):151-159.

60. Song TK, Harris EJ Jr, Raghavan S, Norton JA. Major blood vessel reconstruction during sarcoma surgery. Arch Surg. 2009;144(9): $817-822$.

61. Schwarzbach MH, Hormann Y, Hinz U, et al. Clinical results of surgery for retroperitoneal sarcoma with major blood vessel involvement. J Vasc Surg. 2006;44(1):46-55.

62. Kameyama M, Nakamori S, Imaoka S, et al. [Composite resection of sciatic nerve for local recurrence of rectal cancer]. Gan To Kagaku Ryoho. 1993;20(11):1689-1691.

63. Shaikh I, Aston W, Hellawell G, et al. Extended lateral pelvic sidewall excision (ELSiE): an approach to optimize complete resection rates in locally advanced or recurrent anorectal cancer involving the pelvic sidewall. Tech Coloproctol. 2015;19(2):119-120.

64. Shaikh I, Aston W, Hellawell G, et al. Extended lateral pelvic sidewall excision (ELSiE): an approach to optimize complete resection rates in locally advanced or recurrent anorectal cancer involving the pelvic sidewall. Tech Coloproctol. 2014;18(12):1161-1168.

65. Bickels J, Wittig JC, Kollender Y, Kellar-Graney K, Malawer MM, Meller I. Sciatic nerve resection: is that truly an indication for amputation? Clin Orthop Relat Res. 2002(399):201-204.

66. Brooks AD, Gold JS, Graham D, et al. Resection of the sciatic, peroneal, or tibial nerves: assessment of functional status. Ann Surg Oncol. 2002;9(1):41-47.

67. Mannaerts GH, Rutten HJ, Martijn H, Groen GJ, Hanssens PE, Wiggers T. Abdominosacral resection for primary irresectable and locally recurrent rectal cancer. Dis Colon Rectum. 2001;44(6):806-814.

68. Sagar PM, Gonsalves S, Heath RM, Phillips N, Chalmers AG. Composite abdominosacral resection for recurrent rectal cancer. Br J Surg. 2009;96(2):191-196.

69. Kido A, Koyama F, Akahane M, et al. Extent and contraindications for sacral amputation in patients with recurrent rectal cancer: a systematic literature review. J Orthop Sci. 2011;16(3):286-290.

70. Ramamurthy R, Bose JC, Muthusamy V, Natarajan M, Kunjithapatham D. Staged sacrectomy-an adaptive approach. J Neurosurg Spine. 2009; 11(3):285-294.
71. Fourney DR, Rhines LD, Hentschel SJ, et al. En bloc resection of primary sacral tumors: classification of surgical approaches and outcome. J Neurosurg Spine. 2005;3(2):111-122.

72. Stener B, Gunterberg B. High amputation of the sacrum for extirpation of tumors. Principles and technique. Spine (Phila Pa 1976). 1978; 3(4):351-366.

73. Wanebo HJ, Antoniuk P, Koness RJ, et al. Pelvic resection of recurrent rectal cancer: technical considerations and outcomes. Dis Colon Rectum. 1999;42(11):1438-1448.

74. Wanebo HJ, Gaker DL, Whitehill R, Morgan RF, Constable WC. Pelvic recurrence of rectal cancer. Options for curative resection. Ann Surg. 1987; 205(5):482-495.

75. Dozois EJ, Privitera A, Holubar SD, et al. High sacrectomy for locally recurrent rectal cancer: Can long-term survival be achieved? J Surg Oncol. 2011;103(2):105-109.

76. Milne T, Solomon MJ, Lee P, et al. Sacral resection with pelvic exenteration for advanced primary and recurrent pelvic cancer: a singleinstitution experience of 100 sacrectomies. Dis Colon Rectum. 2014; 57(10):1153-1161.

77. Shaikh I, Holloway I, Aston W, et al; Complex Cancer Clinic St Mark's Hospital London. High subcortical sacrectomy: a novel approach to facilitate complete resection of locally advanced and recurrent rectal cancer with high (S1-S2) sacral extension. Colorectal Disease. 2016; 18(4):386-392.

78. Hugate RR Jr, Dickey ID, Phimolsarnti R, Yaszemski MJ, Sim FH. Mechanical effects of partial sacrectomy: when is reconstruction necessary? Clin Orthop Relat Res. 2006;450:82-88.

79. Beynon J, Davies PW, Biol M, et al. Perioperative blood transfusion increases the risk of recurrence in colorectal cancer. Dis Colon Rectum. 1989;32(11):975-979.

80. Brown KG, Solomon MJ, Austin KK, Lee PJ, Stalley P. Posterior high sacral segmental disconnection prior to anterior en bloc exenteration for recurrent rectal cancer. Tech Coloproctol. 2016;20(6):401-404.

81. Wanebo HJ, Whitehill R, Gaker D, Wang GJ, Morgan R, Constable W. Composite pelvic resection. An approach to advanced pelvic cancer. Archives of Surgery. 1987;122(12):1401-1406.

82. Lopez MJ, Luna-Pérez P. Composite pelvic exenteration: is it worthwhile? Ann Surg Oncol. 2004;11(1):27-33.
OncoTargets and Therapy

\section{Publish your work in this journal}

OncoTargets and Therapy is an international, peer-reviewed, open access journal focusing on the pathological basis of all cancers, potential targets for therapy and treatment protocols employed to improve the management of cancer patients. The journal also focuses on the impact of management programs and new therapeutic agents and protocols on

\section{Dovepress}

patient perspectives such as quality of life, adherence and satisfaction The manuscript management system is completely online and includes a very quick and fair peer-review system, which is all easy to use. Visit http://www.dovepress.com/testimonials.php to read real quotes from published authors. 